\title{
FRAUD RISK ASSESSMENT: A CONCEPTUAL FRAMEWORK FOR INTERNAL AUDITORS TO DETECT FINANCIAL STATEMENT FRAUD
}

Mrs BM van Wyk (Maud) University of South Africa (Unisa)

\begin{abstract}
Fraud is a global problem, often prompting the question "Why did the auditors not detect the fraud?" after corporate fraud disasters have occurred. Despite the existence of several risk assessment methodologies that can be used by internal auditors to help identify fraud risks, these methodologies provide little guidance for internal auditors who are grappling with their perceived role in fraud risk management. The purpose of the research undertaken for this study was to provide a conceptual framework outlining the various fraud risk assessment methodologies that may be used by internal auditors to detect financial statement fraud.
\end{abstract}

The two main strategies identified in the literature review for recognising the risk of fraud are the identification of red flags and the assessment of

\section{Introduction}

Corruption and fraud are part of the society we live in. This realisation is brought home to the public at large every day. You only have to open a newspaper, or listen to the news, to be reminded of it. In its 2014 Report to the Nations on Occupational Fraud \& Abuse, the Association of Certified Fraud Examiners (ACFE) concluded that despite regional findings differing slightly from each other, occupational fraud remains a global problem (ACFE 2014: 5).

Irrespective of the region in which the fraud occurs (ACFE 2012: 5), the characteristics of both the fraudster and the anti-fraud control measures remain similar. This often leads to the question of why auditors do not detect fraud during standard audit assignments (Moeller 2004: 10). Research and surveys that have been conducted by auditing firms such as KPMG, Deloitte, PWC and Ernst \& Young show that fraud risk. The study identified the primary characteristics of risk assessment methodologies such as interviewing, brainstorming and financial analysis, as methods that can be successfully applied by internal auditors.

The findings of the study are useful in informing the continued professional training needs of internal auditors, as they provide a framework that internal auditors can use for conducting generic fraud risk assessments, particularly where financial statement fraud is involved.

Key words - Internal auditor, fraud risk assessment, fraud risk assessment methodologies, interviews, brainstorming, financial analysis, red flags

auditors (both internal and external) do not detect fraud as often as the public may expect. The public expects that auditors, because of their education and training, should be responsible for the detection of fraud (Singleton, Singleton, Bologna \& Lindquist, 2006: 78).

In order to understand the concept of financial statement fraud, one has to be aware of what is regarded as fraud and where financial statement fraud fits into the definition of fraud. There is no single definition of financial statement fraud and professional bodies such as the South African Institute of Chartered Accountants (SAICA), the Institute of Internal Auditors (IIA) and the ACFE all have their own definitions. However, both the various professional bodies and writers on the topic make it clear that, with financial statement fraud, management is involved, the fraud is intentional and it causes damage to stakeholders. In addition, financial statement fraud undermines the entire financial reporting pro 
cess - the quality, the reliability and also the integrity of the process (Rezaee \& Riley 2010: 4).

The most effective internal controls to protect the reliability and integrity of the financial reporting process are overlooked by many organisations, as well as those in control of the governance of organisations. Such controls include surprise audits and targeted fraud risk assessments (ACFE 2014: 5). Although whistle-blowing and tip-offs are among the most successful detection methods (ACFE 2014: 4), they are regarded as part of the corporate culture and not part of corporate controls such as routine internal audit engagements, fraud risk management procedures, the reporting of suspicious transactions, corporate security and the rotation of personnel (PWC Global Economic Crime Survey 2014: 41).

In terms of the professional standards of both internal and external auditors, the prevention and detection of fraud is regarded as being the responsibility of management and those who govern an organisation (IIA 2009: 10; SAICA ISA 240 2009: par 4).

It is incumbent on internal auditors to assist management in the prevention and detection of fraud (IIA 2009: 2). According to Martin and Sanders (2009: 1), internal auditors have always had a fundamental role to play in

\section{Purpose of study and research questions}

The study on which this article is based focused on risk assessment methodologies for identifying improper revenue recognition fraud risks, because this is one of the most common methods used to commit financial statement fraud (Skalak, Golden, Clayton \& Pill 2011: 435). Therefore, the purpose of this study was to provide a conceptual framework for use by internal auditors in identifying fraud risks using generic fraud risk assessment methodologies. In order to support the purpose of this study the following research questions the deterrence of fraud, as they are in a position in companies to detect both financial statement and other fraud. There are various Internal Audit Standards that refer to fraud and the internal auditor's role and responsibility in relation to the detection and prevention of fraud, and in the monitoring of fraud risk. These standards all refer to the way in which the internal auditor should take fraud risk, the probability of fraud and the reporting thereof into account when planning and carrying out an internal audit assignment.

The introduction to the Deloitte Internal Audit Fraud Survey (2010: 1) states that the evolution of the internal audit mandate has meant an increased dependence on the monitoring, detection and investigation abilities of internal audit when it comes to fraud. It is also clear that the Practice Guide (IIA 2009: 2) recognises that the internal audit activity has a responsibility regarding the detection of fraud in general.

External audit standards (SAICA ISA 240 2009: par 16; ISA 315 2009: par 5-10) are specific about fraud risk assessment methodologies; in contrast internal auditing standards tend to be generic about which fraud risk assessment methodologies should be used to identify fraud risks and to detect financial statement fraud (IIA 2009: 2).

were answered:

- What is a fraud risk assessment and what is the role internal auditors' play in the fraud risk assessment process?

- What are fraud risk assessment methodologies and how can they be used to identify financial statement fraud schemes involving improper revenue recognition? 


\section{Research approach and methodology}

This study focused specifically on the guidance given to internal auditors by the International Standards for the Professional Practice of Internal Auditing (IIA Standards) on their responsibilities in the detection of fraud, including financial statement fraud, and the methodologies that may be used to identify financial statement fraud schemes. These fraud detection methodologies are described in detail in the external audit standards (SAICA ISA 240 2009: par 16), but the IIA Standards are not particularly specific. The IPPF Practice Guide: Internal Auditing and Fraud (IIA 2009) stipulates that internal auditors have a responsibility to obtain sufficient skills and competencies to fulfil their responsibilities regarding the prevention and detection of fraud (IIA 2009: 11).

The research approach followed in this study encompassed the development of a conceptual framework based on an extended literature review,

\section{The role of internal audit in fraud risk assessment}

In terms of the definition of internal auditing by the Institute of Internal Auditors, the primary role of internal auditors is to provide the organisation with an independent and objective assurance and consulting service (IIA Standards 2013: i). This service should add value to the organisation and improve its operations. A systematic and disciplined approach to the evaluation of the risk management, control and governance processes is therefore adopted in order to improve the processes and, in turn, enable the organisation to accomplish its objectives and goals (IIA Standards 2013: i).

Internal auditors should seek to improve risk management, control and governance processes, which will result in the continuous improvement of which formed a self-contained study and was not merely the first phase of a conventional empirical study (Mouton 2005: 86). The aim of an extended literature review is to provide an overview of the research conducted in a specific field and such a review should aim at improving the in-depth understanding of the identified problem (De Vos, Strydom, Fouchè \& Delport 2011: 134; Hofstee 2006: 121).

Other researchers have dealt with internal audit's involvement in fraud investigations, but none have so far considered the specific role of internal auditors regarding annual financial statement (AFS) fraud. This is usually covered in the statutory audit engagements done by traditional external auditors. In this study, no empirical investigation was carried out because the objective was to establish a framework for internal auditors looking into AFS fraud, using existing guidelines, standards and frameworks.

organisational performance. According to IIA Standard 2120.A1 (2013), the internal audit activity (IAA) must evaluate the abovementioned processes in order to establish the reliability and integrity of both operational and financial information.

It is obvious from the definition of internal auditing that the IAA has a role to play in the risk management process. It may therefore be assumed that internal audit responsibilities include the prevention and detection of fraud (Taylor 2011: 44). At the very least, the internal auditor must possess sufficient knowledge of fraud to be able to evaluate fraud risks and controls, identify fraud risks and assess related controls (IIA Standard 1210.A2 2013). Rezaee and Riley (2010: 208) maintain that internal auditors are in the best position to detect financial statement fraud. Although external auditors are traditionally held responsible for the detection of financial statement fraud, the internal auditors' role in 
the prevention of such fraud will consist of limiting the opportunities available to commit the fraud and assessing possible financial statement fraud risks (Rezaee \& Riley 2010: 210).

In order to ensure that internal auditors effectively address fraud risks and the management of such risks during the year, the chief audit executive (CAE) must include the management controls that pertain to fraud in the risk-based annual audit plan. By testing high-risk processes and identifying fraud indicators (red flags)

\section{A conceptual framework} for internal auditors when assessing fraud risk and detecting financial statement fraud

The exposure of fraudulent corporate activities, including the presentation of fraudulent financial statements, can be extremely complex because the perpetrators will do everything in their power to conceal it (Reding, Sobel, Anderson, Head, Ramamoorti, Salamasick, \& Riddle, 2009: 8-31). However, fraudulent activities may be uncovered by identifying fraud indicators and being alert to red flags, such as the existence of a poor internal control environment and an ineffective audit committee. Once identified, fraud risks must be evaluated in order to understand their significance, as well as to consider the effectiveness of the fraud risk

\subsection{The fraud risk assessment process}

Although there will be costs involved in performing a fraud risk assessment, the cost to underestimate fraud risk will be much higher because of the consequences of expressing an within and outside the business, the CAE will improve the probability that potential fraud will be detected. In every audit assignment the possibility of fraud should be considered, and fraud risk, fraud controls and errors should all be evaluated to determine whether there is some indication of it. The conceptual framework identified by this research, which sets out the various fraud risk assessment methodologies to be used, will assist the IAA in the detection of financial statement fraud.

management programme that has been implemented to address these risks (Rezaee 2005: 294).

It is therefore necessary for internal auditors to develop and implement specific techniques and procedures to ascertain whether the internal control systems have been compromised and to establish the extent to which an organisation is at risk of fraud (Kranacher, Riley, \& Wells, 2011: 175). The tools used by management and internal auditors to systematically identify fraud risks are called fraud risk assessments. In financial statement fraud, such assessments should focus on specific fraud schemes and previously reported cases of fraud to establish whether there have been any control failures. The methodologies to achieve this include brainstorming, interviewing, analytical procedures and reviewing previously committed fraud (IIA 2009: 16). There are two general strategies which may be used to identify the risk of fraud, namely, the identification of fraud red flags and targeted fraud risk assessments (Kranacher et al. 2011: 182).

incorrect opinion on the financial statements (Wood, 2012, 24). In order to facilitate a structured and focused process to establish where the organisation is at risk of fraud or to detect fraud which has already been committed, it is essential that the internal auditor plan the process in the same way in which he/she would plan the auditing process at the beginning of a 
conventional auditing engagement (Manning 2011:

\subsection{Fraud risk assessment methodologies}

There are certain generic methodologies that may be used during the fraud risk assessment process. ISA 240 (SAICA 2009: par A7-A12) discusses the following basic methodologies: discussion among team members (also known as brainstorming); interviewing members of management regarding their assessment of fraud risk and related controls; and performing

\subsubsection{Red flags}

In the accounting context, red flags result from conducting a set of tests, the results of which point towards increased risk levels related to a set of financial statements (Feroz 2008). Red flags may be somewhat of a cliché, but an internal auditor would have to be courageous to ignore them (Taylor 2011: 131). In financial statement fraud there are specific red flags which may relate to various fraud schemes. There may also be behavioural red flags, such as lifestyle or gambling habits, which could indicate that fraud is being committed.

Red flags may be divided into either personal or environmental fraud indicators. The environmental fraud indicators that may encourage a culture of fraudulent behaviour are those factors which are related to the organisation, and the control environment and ethical culture created by management. In a poor control environment there is a greater possibility that fraud may be committed because the opportunity to commit the fraud exists, as well as the possibility of

\subsubsection{Interviewing to establish fraud risks}

One of the specific fraud risk assessment methodologies that may be used in detecting fraud is interviews. This is strongly recommended by Practice Advisory 2120-1 (IIA Standards 2013: par 8) and involves conducting interviews with all levels of
571).

analytical procedures and analysing ratios. In addition, Kranacher et al. (2011: 182) suggest that red flags should be evaluated in order to identify possible fraud risk areas. Such red flags do not prove the existence of fraud but are a signal that auditors should be alert to the possibility of fraud being committed (Kranacher et al. 2011: 24). These methodologies all have the potential to identify anomalies which will, in turn, lead to further investigation.

not being caught. If top management creates a culture of dishonesty it may result in management itself behaving fraudulently or exerting undue pressure on the staff of the organisation by making unrealistic demands and creating unrealistic targets. This may lead to fraudulent behaviour which is driven by the desire to survive. In addition, if the impression exists that fraudulent behaviour is tolerated and that staff members may get away with it, this will create an environment that is conducive to fraud being committed (Crawford \& Weirich 2011: 354).

Fraud is a crime involving the deliberate concealment of certain actions and the deception of the people concerned and, thus, red flags will not always be clearly visible or easy to recognise and interpret (Skalak et al. 2011: 238). It is important to remember that fraud risk factors are not the same as concrete evidence that fraud has been committed; they are merely an indication of the possibility that fraud may be committed.

management in order to determine both business risks and business objectives.

During these interviews the internal auditor will endeavour to obtain information on possible fraud risk indicators, such as a lack of segregation of duties, the presence of performance incentives and declarations of conflicts of interest, to evaluate the 
Proc. of the Third Intl. Conf. on Advances in Management, Economics and Social Science - MES 2015.

Copyright $($ Institute of Research Engineers and Doctors, USA .All rights reserved.

ISBN: 978-1-63248-081-1 doi: 10.15224/ 978-1-63248-081-1-80

organisational culture, including the control

\subsubsection{Discussion among team members (brainstorming)}

The process of conducting a risk assessment does not differ significantly from the decision-making process. One way in which to ensure that a group makes a decision is to make use of brainstorming techniques (Singleton et al. 2006: 197). Brainstorming, also known as discussion among team members, is a technique by means of which both more experienced and less experienced team members sit down together and all have an equal opportunity to discuss, in this case, possible fraud risk indicators. The aim of brainstorming is not only to identify possible areas of fraud risk but also to establish the mindset of the team throughout the assurance engagement (Skalak et al. 2011: 250).

During brainstorming sessions, internal auditors will be

\subsubsection{Analytical procedures}

The analysis of the financial statements, also known as analytical procedures, is another technique which may be used to identify fraud risk indicators. Financial analysis is conducted by using vertical analysis, horizontal analysis and ratio analysis to identify material fluctuations in the financial statements (Wells 2005: 357). This analysis may be done over one or more financial periods, or the results may be compared to other non-financial information obtained such as

\section{Conclusion and}

\section{recommendations}

\subsection{Conclusion}

The study identified the primary risk assessment methodologies as being interviewing, brainstorming, financial analysis and identifying red flags, and showed how internal auditors may use them successfully. The adoption of these practices should reduce the environment (Wells \& Gill 2007: 63).

able to discuss the possibility of fraudulent activities taking place with the fraud triangle in mind. This will assist the team to identify possible opportunities to commit fraud while taking account of the incentives and pressures that have been identified in the organisation.

The focus of such discussions should be on the risks of material misstatement of the financial statements resulting from fraud, as well as about the areas in which management may override controls and whether it is possible to place reliance on the integrity of management (Skalak et al. 2011: 250). In other words, brainstorming is a way in which to generate ideas on how fraud may be committed and concealed (Crumbley, Heitger, \& Smith, 2007: 4-21). In practice, brainstorming may be also be used to identify and discuss possible ways in which to respond to any fraud risks identified (Ramos 2003: 29).

industry or competitor data (Crumbley et al. 2007: 435). Analytical procedures may be used to support other evidence relating to financial statement fraud or to identify suspected fraud in the financial statements. The findings of these analytical procedures may be corroborated by non-financial evidence obtained during the interviewing phase or may be used to follow up on previously identified red flags (Hopwood, Leiner, \& Young. 2008: 227).

propensity for fraud and improve the veracity of the annual financial statements.

The duties of the IAA include the evaluation of the control processes for effectiveness and efficiency, including controls relating to the reliability and integrity of both financial and operational information (IIA Standard 2130 2013). The procedures which have been developed to identify fraudulent activities must be 
Proc. of the Third Intl. Conf. on Advances in Management, Economics and Social Science - MES 2015.

Copyright $(\subseteq$ Institute of Research Engineers and Doctors, USA .All rights reserved.

ISBN: 978-1-63248-081-1 doi: 10.15224/ 978-1-63248-081-1-80

adapted on an ongoing basis to ensure that any changes in potential fraud risks are addressed (Richards, Melancon \& Ratley 2012: 34). The CAE must form an overall opinion on the effectiveness and efficiency of the systems of internal controls and report the results to the board of directors and management (IIA Standards 2013: Practice Advisory

\subsection{Recommendations}

There is a need for internal auditors to be part of the fraud risk management process and the following recommendations may be considered to empower internal auditors to fulfil their roles and responsibilities optimally in the detection of financial statement fraud:

- The education and training of internal auditors should include the suggested conceptual

\section{LIST OF REFERENCES}

Association of Certified Fraud Examiners (ACFE). 2012. Report to the Nations on Occupational Fraud \& Abuse. Available from: http://www.acfe.com/uploadedFiles/ACFE_Website/Co ntent/rttn/2012-report-to-nations.pdf [Accessed 201305-16]

Association of Certified Fraud Examiners (ACFE). 2014. Report to the Nations on Occupational Fraud \& Abuse. Available from: http://www.acfe.com/rttn/docs/2014-report-tonations.pdf [Accessed 2015-04-06]

Crawford, R.L. \& Weirich, T.R. 2011. Fraud guidance for corporate counsel reviewing financial statements and reports. Journal of Financial Crime, 18(4): 347360.

Crumbley, D.L., Heitger, L.E. \& Smith, G.S. 2007. Forensic and investigative accounting. 3rd edition. Chicago, IL: $\mathrm{CCH}$.

Deloitte. 2010. Internal audit fraud survey. Available at: https://www.deloitte.com/view/en_US/us/Insights/center s/centers-forensiccenter/063d8be812b8b210VgnVCM2000001b56f00aRC RD.htm. [Accessed 2013-02-19]

De Vos, A.S., Strydom, H., Fouchè, C.B. \& Delport, C.S.L. 2011. Research at grass roots. Pretoria: Van
2130-1 par 3). Where discrepancies are identified, the impact of such discrepancies must be determined and the corrective actions to be taken by management should be established (IIA Standards 2013: Practice Advisory 2130-1 par 9).

framework and the underlying principles. Internal auditors should be trained to implement the methodologies practically in their day-today operations and in the execution of audit engagements.

- The internal audit charter should be specific in describing the roles and responsibilities expected of internal auditors in the detection of financial statement fraud.

Schaik.

Feroz, E.H. 2008. Red flags in accounting. Available from:

http://papers.ssrn.com/sol3/papers.cfm?abstract_id=1 248776 [Accessed: 21 February 2013]

Hofstee, E. 2006. Constructing a good dissertation: A practical guide to finishing a master's, MBA or PhD on schedule. Sandton: EPE.

Hopwood, W.S., Leiner, J.J., \& Young, G.R. 2008.

Forensic accounting. New York: McGraw Hill/Irwin.

Kranacher, M., Riley, R.A. Jr \& Wells, J.T. 2011. Forensic accounting and fraud examination. USA: John Wiley.

Manning, G.A. 2011. Financial investigation and forensic accounting. Boca Raton, FL: CRC Press.

Martin, K.A. and D.E. Sanders. 2009.

Characteristics of Internal Audits and

Fraud Detection. The IIA Research

Foundation.

Moeller, R.R. 2004. Sarbanes-Oxley and the new internal auditing rules. New Jersey: John Wiley. 
Proc. of the Third Intl. Conf. on Advances in Management, Economics and Social Science - MES 2015.

Copyright (C) Institute of Research Engineers and Doctors, USA .All rights reserved.

ISBN: 978-1-63248-081-1 doi: 10.15224/ 978-1-63248-081-1-80

Mouton, J. 2005. How to succeed in your master's and doctoral studies: A South African guide and resource book. Pretoria: Van Schaik.

PriceWaterhouseCoopers (PWC) 2014.Economic Crime: A threat to business globally. $7^{\text {th }}$ PWC Global Economic Crime Survey. Available at http://www.pwc.com/gx/en/economic-crimesurvey/downloads.jhtml [Accessed: 19 April 2015]

Ramos, M. 2003. Auditor's responsibility for fraud detection. Journal of Accountancy, January: 28-36.

Reding, K.F., Sobel, P.J., Anderson, U.L., Head, M.J., Ramamoorti, S., Salamasick, M. \& Riddle, C. 2009. Internal auditing: Assurance \& consulting services. 2nd edition. Altemonte Springs, FL: The Institute of Internal Auditors Research Foundation (IIARF).

Rezaee, Z. 2005. Causes, consequences, and deterrence of financial statement fraud. Critical Perspectives on Accounting, vol. 16: 277-298.

Rezaee, Z. \& Riley, R., 2010. Financial statement fraud: Prevention and detection. Hoboken, NJ: John Wiley.

Richards, D.A., Melancon, B.C. \& Ratley, J.D. 2012. Managing the business risk of fraud: A practical guide. Available at: https://na.theiia.org/standardsguidance/Public\%20Documents/fraud\%20paper.pdf [Accessed 2013-03-14].

SAICA Handbook. 2009/2010. International standards on auditing and assurance pronouncements adopted by the IRBA to be applied by registered auditors in South Africa. Vol. 2. Durban: LexisNexis.

Singleton, T.W., Singleton, A.J., Bologna, G.J. \& Lindquist, R.J. 2006. Fraud auditing and forensic accounting. New Jersey: Wiley.

Skalak, S.L., Golden, T., Clayton, M. \& Pill, J. 2011. A guide to forensic accounting investigation. New Jersey: Wiley.

Taylor, J. 2011. Forensic accounting. England: Pearson Education.

The Institute of Internal Auditors (IIA). 2009. IPPF

Practice guide: Internal auditing and fraud. Available at: https://na.theiia.org/standardsguidance/recommended-guidance/practiceguides/Pages/Internal-Auditing- and-Fraud-PracticeGuide.aspx [Accessed 18 May 2013]

The Institute of Internal Auditors (IIA). 2013. International Standards for the Professional Practice of Internal Auditing (IIA Standards). South African student edition. Bedfordview: IIA.

Wells, J.T. 2005. Principles of fraud examination. New Jersey: Wiley.

Wells, J.T. \& Gill, D. 2007. Assessing fraud risk. Journal of Accountancy, October: 63-65.

Wood, L.I. 2012. The impact of decision aid use on the dilution effect when assessing fraud. Journal of finance and Accountancy, April: 23-42. 